ARTICLE

\title{
Global health effects of future atmospheric mercury emissions
}

Yanxu Zhang $\mathbb{1}^{1 凶}{ }^{凶}$, Zhengcheng Song ${ }^{1}$, Shaojian Huang ${ }^{1}$, Peng Zhang ${ }^{1}$, Yiming Peng ${ }^{1}$ Peipei $\mathrm{Wu}^{1}$, Jing $\mathrm{Gu}^{1}$, Stephanie Dutkiewicz ${ }^{2}$, Huanxin Zhang ${ }^{3,4}$, Shiliang $\mathrm{Wu}^{4,5}$, Feiyue Wang ${ }^{6}{ }^{6}$, Long Chen (1) ${ }^{7}$, Shuxiao Wang (1) ${ }^{8,9} \&$ Ping $\mathrm{Li}^{10}$

Mercury is a potent neurotoxin that poses health risks to the global population. Anthropogenic mercury emissions to the atmosphere are projected to decrease in the future due to enhanced policy efforts such as the Minamata Convention, a legally-binding international treaty entered into force in 2017. Here, we report the development of a comprehensive climate-atmosphere-land-ocean-ecosystem and exposure-risk model framework for mercury and its application to project the health effects of future atmospheric emissions. Our results show that the accumulated health effects associated with mercury exposure during 2010-2050 are $\$ 19$ (95\% confidence interval: 4.7-54) trillion (2020 USD) realized to 2050 (3\% discount rate) for the current policy scenario. Our results suggest a substantial increase in global human health cost if emission reduction actions are delayed. This comprehensive modeling approach provides a much-needed tool to help parties to evaluate the effectiveness of $\mathrm{Hg}$ emission controls as required by the Minamata Convention.

\footnotetext{
${ }^{1}$ School of Atmospheric Sciences, Nanjing University, Nanjing, P. R. China. ${ }^{2}$ Department of Earth, Atmospheric and Planetary Sciences, Massachusetts Institute of Technology, Cambridge, MA, USA. ${ }^{3}$ Department of Chemical and Biochemical Engineering, University of lowa, lowa City, IA, USA. ${ }^{4}$ Geological and Mining Engineering and Sciences, Michigan Technological University, Houghton, MI, USA. ${ }^{5}$ Civil and Environmental Engineering, Michigan Technological University, Houghton, MI, USA. ${ }^{6}$ Centre for Earth Observation Science, Department of Environment and Geography, University of Manitoba, Winnipeg, MB, Canada. ${ }^{7}$ Key Laboratory of Geographic Information Science (Ministry of Education), School of Geographic Sciences, East China Normal University, Shanghai, P. R. China. ${ }^{8}$ School of Environment, State Key Joint Laboratory of Environment Simulation and Pollution Control, Tsinghua University, Beijing, P. R. China. ${ }^{9}$ State Environmental Protection Key Laboratory of Sources and Control of Air Pollution Complex, Beijing, P. R. China. ${ }^{10}$ State Key Laboratory of Environmental Geochemistry, Institute of Geochemistry, Chinese Academy of Sciences, Guiyang, P. R. China. ${ }^{凶}$ email: zhangyx@nju.edu.cn
} 
$\mathrm{M}$ ercury $(\mathrm{Hg})$ is a global pollutant, and its organic form, methylmercury ( $\mathrm{MeHg}$ ) is associated with neurocognitive deficits in human fetuses and cardiovascular effects in adults ${ }^{1,2}$. Human exposure to $\mathrm{MeHg}$ is predominantly via the consumption of food (e.g., seafood and rice) $)^{3,4}$. The annual death from the fatal heart attack that is attributable to $\mathrm{MeHg}$ exposure is estimated to be over 10,000 in China ${ }^{5}$. Economic losses from intelligence quotient (IQ) decrease of developing brains associated with $\mathrm{MeHg}$ exposure has been estimated at $\$ 16$ billion in the U.S. and European Union ${ }^{3,5,6}$. To protect human health and the environment, the Minamata Convention on Mercury, a legally-binding international treaty, took effect in August 2017 to reduce anthropogenic emissions of $\mathrm{Hg}$ (https:// www.mercuryconvention.org).

Future projections of global primary anthropogenic $\mathrm{Hg}$ emissions vary drastically driven by underlying social-economic and technological change $e^{7,8}$. The re-emissions from soils and oceans that receive past atmospheric depositions of $\mathrm{Hg}$ (legacy emissions) are also important sources, the magnitude of which is 2-3 times larger than the primary anthropogenic emissions ${ }^{9,10}$. The $\mathrm{MeHg}$ exposure is influenced by a chain of processes including atmospheric emission, atmospheric transport and deposition, airsea exchange, air-land exchange, chemical transformation (especially $\mathrm{Hg}$ methylation), food web transfers, and human food intake ${ }^{11}$. These processes are modulated by the fluctuation and change in climate, land-use, ocean circulation, and ecosystem functions ${ }^{12,13}$. Earlier studies do not link emissions to exposure changes $^{3,14-17}$. Later efforts in global $\mathrm{Hg}$ exposure modeling have considered only a subset of these processes. For instance, using atmospheric transport models, atmospheric deposition is considered as an indicator for the level of $\mathrm{MeHg}$ in seafood ${ }^{5,11,13}$. Zhang et al. ${ }^{13}$ included the impact of changing climate, land-use, and land-cover on atmospheric transport and deposition, and Amos et al. ${ }^{18}$ and Angot et al. ${ }^{19}$ considered the response of land/ ocean re-emissions to anthropogenic emission change with a box model.

In this study, we develop a more comprehensive approach to project the change in human $\mathrm{MeHg}$ exposure responding to $\mathrm{Hg}$ emission changes. We integrate changes in anthropogenic emissions, climate, and biogeochemical cycles. We use a coupled three-dimensional atmosphere/ocean and two-dimensional land model. The $\mathrm{Hg} / \mathrm{MeHg}$ levels in the environment are used to scale an intake inventory of $\mathrm{MeHg}$ for different countries, which are further used to calculate the health impact based on epidemiology-based dose-response relationships (see "Methods" for details). We present a map of MeHg-related health risks for all the countries. Based on this, we translate future $\mathrm{Hg}$ emission projections into health risks, and to help parties and stakeholders to evaluate impacts from changes in $\mathrm{Hg}$ emissions.

\section{Results and discussion}

Baseline Hg-related health risk. We estimate that the global health impacts associated with $\mathrm{MeHg}$ exposure for the general population are $\$ 117$ billion (2020 USD adjusted by purchasing power parity, PPP), contributed by $1.2 \times 10^{7}$ points of IQ decrements (0.086 point per-fetus) and 29,000 deaths per year at present-day. We include two health endpoints as a consequence of food MeHg exposure: decrement in IQ of newborns and fatal heart attack (FHA) for general populations. The IQ decrement is transferred to lifelong earnings loss based on the projections of the population and economic growth of each country ${ }^{3,20}$. The economic loss from FHA is calculated based on a value of statistical life (VSL) approach, which is scaled by the PPP adjusted per-capita GDP value of individual countries ${ }^{11}$. The exposures from seafood (including fish and aquatic animals), freshwater fish (also including other aquatic animals), and rice consumption are included here with the $\mathrm{MeHg}$ concentrations from literature (see Method for more details and the Supporting Information for detailed data).

We find that the $\mathrm{MeHg}$ exposure and health risk are associated with the food intake structures of different countries. Coastal countries with large seafood consumption have the largest $\mathrm{MeHg}$ exposure, and rice and freshwater fish consumption are nonnegligible in some countries (Fig. S5). The highest per-capita seafood $\mathrm{MeHg}$ exposure is found in countries with large seafood consumption, such as the Maldives $(33 \mu \mathrm{g} / \mathrm{d})$, Greenland $(16 \mu \mathrm{g} /$ d), Iceland $(15 \mu \mathrm{g} / \mathrm{d})$, and Kiribati $(13 \mu \mathrm{g} / \mathrm{d})$ (Fig. S5). The national average per-capita seafood consumptions are 190, 89, 74, and $48 \mathrm{~kg} / \mathrm{y}$ for these four countries, respectively, which are much higher than the global average of $15 \mathrm{~kg} / \mathrm{y}$ (UN FAO, http://www. fao.org). The lowest risk is found in inland countries with nearly no seafood consumption, such as Ethiopia $(0.0018 \mu \mathrm{g} / \mathrm{d})$, Uganda $(0.0093 \mu \mathrm{g} / \mathrm{d})$, and Chad $(0.014 \mu \mathrm{g} / \mathrm{d})$. The $\mathrm{MeHg}$ exposure from rice is the highest in Southeast Asian countries such as Indonesia $(1.7 \mu \mathrm{g} / \mathrm{d})$, Laos $(0.90 \mu \mathrm{g} / \mathrm{d})$, and Cambodia $(0.77 \mu \mathrm{g} / \mathrm{d})$ (Fig. S5). The contribution of rice to $\mathrm{MeHg}$ exposure has previously been found in communities relying on rice grown in areas heavily contaminated with $\mathrm{Hg}^{4,21}$, whereas our findings highlight the potential importance of rice consumption for the general population. We find the contribution from rice could be dominant in inland countries with large rice consumptions, e.g., Nepal (58\%), Afghanistan (50\%), and Bhutan (45\%). The spatial distribution of the consumption of freshwater fish is similar to that of rice, and the exposure is the highest in Asian countries such as Cambodia $(6.3 \mu \mathrm{g} / \mathrm{d})$, Myanmar $(3.5 \mu \mathrm{g} / \mathrm{d})$, and Japan $(2.9 \mu \mathrm{g} / \mathrm{d})$. The $\mathrm{MeHg}$ exposure from this pathway is also influenced by the fish $\mathrm{MeHg}$ concentrations, which causes relatively high exposure over countries such as Russia $(3.5 \mu \mathrm{g} / \mathrm{d})$ and Finland $(3.2 \mu \mathrm{g} / \mathrm{d})$.

The total health risk of $\mathrm{MeHg}$ reflects the total exposure of the above-discussed pathways. The associated IQ decrease per-fetus is the highest in the Maldives (1.2 points), Greenland (0.60 points), and Iceland (0.56 points), where the exposure from seafood is high. The risk is the lowest in Uzbekistan (0.0040 points), Tajikistan ( 0.0036 points), and Ethiopia (0.0012 points), where the consumption of fish and rice are both low (Fig. 1a). Figure 1c shows the economic loss due to IQ reduction of newborns. Besides $\mathrm{MeHg}$ exposure, the loss reflects the birth rate and income level of countries. The US ranks first by losing $\$ 12$ billion per year, followed by China ( $\$ 7.3$ billion), Japan (\$6.2 billion), and Russia ( $\$ 2.9$ billion). The spatial pattern of the deaths associated with FHA (Fig. 1b) is quite different from that of IQ decrement but reflects the total population and baseline FHA incidence. The most deaths are from populous countries with mild to high per-capita risks, such as China (5600 per year), Russia (3200), Indonesia (3200), and India (2300). Taking into the difference in VSL per death puts Russia the first place $(\$ 9.1$ billion) in economic loss from this pathway, followed by the USA ( $\$ 9.0$ billion), China ( $\$ 7.7$ billion), and Japan ( $\$ 3.2$ billion) (Fig. 1d). Combining the two endpoints results in that the US suffers from a total loss of $\$ 21$ billion per year, followed by China ( $\$ 15$ billion), Russia ( $\$ 12$ billion), and Japan ( $\$ 9.3$ billion) (Fig. 1e). Asia ( $\$ 48$ billion), Europe ( $\$ 34$ billion), and North America ( $\$ 23$ billion) have $90 \%$ of the global health risk, with Africa ( $\$ 6.4$ billion), South America ( $\$ 5.4$ billion), and Oceania ( $\$ 1.5$ billion) contributing the remaining $10 \%$.

Our study estimates the health risk associated with $\mathrm{MeHg}$ exposure based on food intake inventory and food $\mathrm{MeHg}$ concentrations for individual countries at a global scale. Validation data remain sparse but our estimate generally agrees with previous regional-scale studies for China, US and Europe. Our 


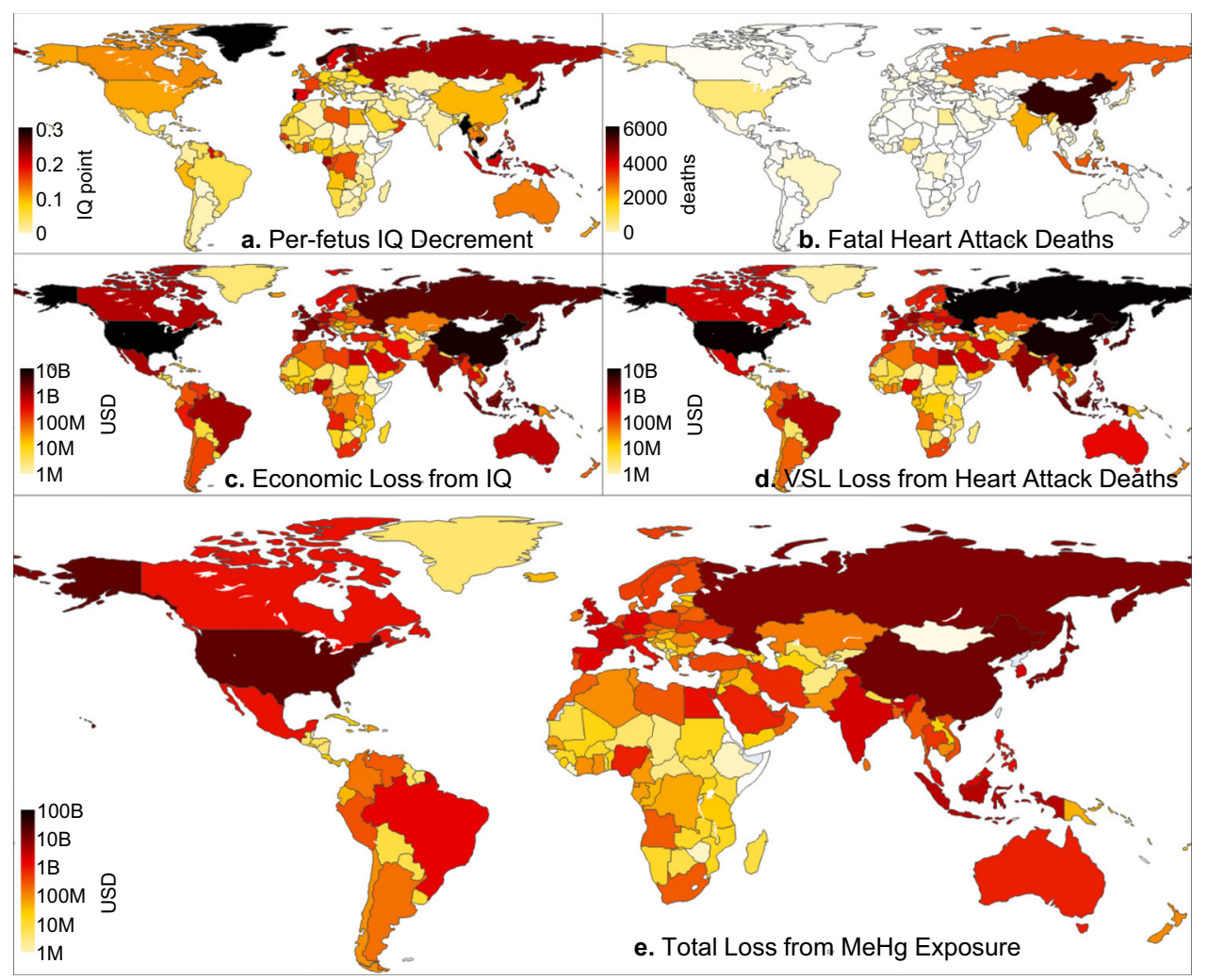

Fig. 1 Global health impact of methylmercury $(\mathbf{M e H g})$ food exposure at present-day. (a) Per-fetus intelligence quotient (IQ) decrement; (b) Fatal heart attack deaths; (c) Economic loss from IQ decrease; (d) Value of statistical life (VSL) loss from fatal heart attacks; (e) Total loss from MeHg exposure (the sum of (c) and (d)). Economic losses are in United States (US) dollars (2020 value and adjusted by purchasing power parity). The gray area indicates missing data and the color scale of (c)-(e) is in the logarithmic scale.

results for the Chinese population ( 0.11 point IQ decrease per fetus and 5600 FHA deaths per year) are slightly lower than Chen et al. (2019) (0.14 points per fetus and 7360 deaths), as we exclude the exposure from other food such as pork, beef, and eggs, which have negligible contribution to the total exposure (except for the eggs and meat from fish-eating seabirds that are consumed by some indigenous populations, e.g., Evers et al. (2003), but there is limited data and may be not important for general populations $)^{22}$. We estimate the per-capita $\mathrm{MeHg}$ exposure from seafood consumption for the US population is $11 \mu \mathrm{g} \mathrm{kg}$ body $\mathrm{wt}^{-1} \mathrm{a}^{-1}$, which agrees with the estimate of Mahaffey et al. (2004) and Sunderland (2007): $7.3-11 \mu \mathrm{g} \mathrm{kg}^{-1} \mathrm{a}^{-1}$. We estimate a total of 500,000 points per year of IQ decrements in the US at present-day, which is higher than previous estimates $(264,000-285,000$ points per year $)^{6,23}$, but our estimate $(720,000$ points) for Europe agrees well with Bellinger et al. (2013), who calculated 640,000 points of IQ loss based on hair $\mathrm{Hg}$ concentrations among women of reproductive age.

The modeled spatial pattern agrees with the distribution of $\mathrm{Hg}$ biomarkers in general populations from individual countries (Fig. S4). We estimate the hair and blood $\mathrm{Hg}$ concentrations based on the total food $\mathrm{MeHg}$ exposure and pharmacokinetics models (see Method for details), and evaluate them against available human biomarker data in literature as summarized by Basu et al. (2018). The estimated blood $\mathrm{Hg}$ concentrations among the 40 countries where data are available are $2.5 \pm 1.8 \mu \mathrm{g} / \mathrm{L}$ (mean \pm standard deviation), consistent with measured values $(2.2 \pm$ $2.1 \mu \mathrm{g} / \mathrm{L}$ ) with a correlation coefficient of 0.71 (Fig. S4). The measured highest mean blood $\mathrm{Hg}$ concentrations are found in Greenland $(9.2 \mu \mathrm{g} / \mathrm{L})$, which is well captured by our estimate $(10 \mu \mathrm{g} / \mathrm{L}$, rank = 1st). High blood $\mathrm{Hg}$ concentrations are also measured in Cambodia $(9.1 \mu \mathrm{g} / \mathrm{L})$, Spain $(6.0 \mu \mathrm{g} / \mathrm{L})$, Japan $(5.1 \mu \mathrm{g} /$
$\mathrm{L})$, and South Korea $(4.0 \mu \mathrm{g} / \mathrm{L})$, and our estimates agree with these measurements $(4.8,3.4,5.5$, and $4.6 \mu \mathrm{g} / \mathrm{L}$, respectively). A lower correlation coefficient $(0.53)$ is calculated for the estimated and measured hair $\mathrm{Hg}$ concentrations $(n=38)$, but the estimate $(0.40 \pm 0.27 \mu \mathrm{g} / \mathrm{g})$ is within a factor of $\sim 2$ from the measured data $(0.76 \pm 0.48 \mu \mathrm{g} / \mathrm{g}$ ) (Fig. S4). In addition to the $\mathrm{MeHg}$ exposure, the biomarker level subjects to the variability of pharmacokinetic and intrinsic (such as genetics) factors ${ }^{24,25}$. Overall, our results show that human $\mathrm{Hg}$ biomarker levels could be explained by the food $\mathrm{Hg}$ exposure for general populations from individual countries, supporting our approach can be used to assess the baseline risk at present-day and its projection in the future.

Future $\mathrm{Hg}$ emissions. Figure 2 shows global anthropogenic $\mathrm{Hg}$ emissions projections under different scenarios. The global total anthropogenic $\mathrm{Hg}$ emissions are $1890 \mathrm{Mg} \mathrm{yr}^{-1}$ in 2010 with artisanal and small-scale gold mining (ASGM, 37\%) and fossil fuel combustion (25\%) as the two largest sources followed by non-ferrous metals production (10\%) and cement production $(9 \%)^{26}$. Streets et al. (2009) projected $\mathrm{Hg}$ emissions to increase to 4900 and $3900 \mathrm{Mg} \mathrm{yr}^{-1}$ in 2050 under the $\mathrm{A} 1 \mathrm{~B}$ (business as usual) and A2 (a divided world) scenarios, respectively, driven by the increase of coal combustion in developing countries. In a New Policies (NP) scenario, Pacyna et al. ${ }^{8}$ projected the emissions to decrease to $1020 \mathrm{Mg} \mathrm{y}^{-1}$ in 2035. Part of the emission reduction is from fossil fuel combustion and cement production resulting from the co-benefits of greenhouse gas emission control. The $\mathrm{Hg}$ emissions from $\mathrm{Hg}$-containing products are also projected to reduce by $70 \%$ in 2035 compared to the 2010 situation, and the use of $\mathrm{Hg}$ in ASGM is reduced by $46 \%{ }^{8}$. In a Maximum Feasible Reduction (MFR) scenario, the global 


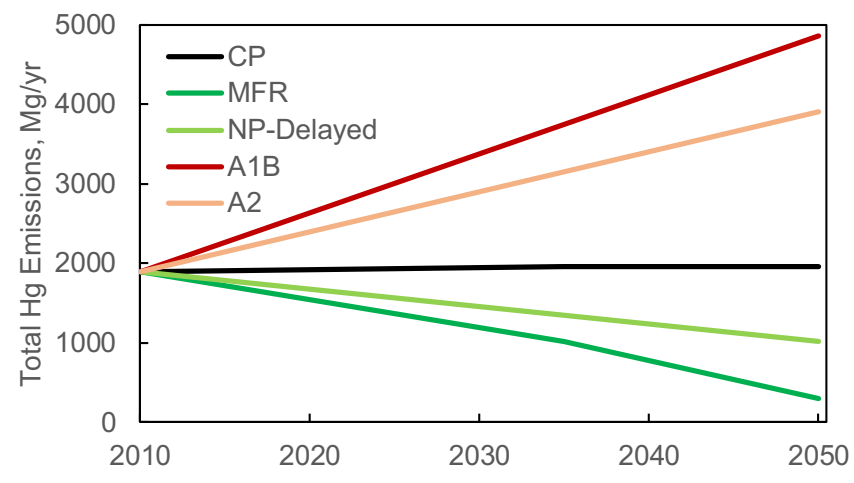

Fig. 2 Projections of global total anthropogenic emission of mercury during 2010-2050 based on different emission scenarios. CP (current policy) scenario assumes a near to constant emissions through 2050. A1B and $\mathrm{A} 2$ are for business as usual and a divided world scenarios with increasing emissions, respectively. MFR (maximum feasible reduction) assumes the application of the best available technologies and aggressive emission reductions. NP-Delayed (new policy delayed) assumes the 2035 goal of the MFR scenario is delayed to 2050.

emissions are projected to reduce to $300 \mathrm{Mg} \mathrm{y}^{-1}$ with the $\mathrm{Hg}$ containing product and ASGM emissions reduced by $95 \%$ and $76 \%$, respectively ${ }^{8}$. The best available technologies are assumed for the industrial and energy sectors without constraints in the economy and increasing demand. Although it was considered an unrealistic scenario for $2035^{8}$, we treat it as an optimistic projection for 2050. We refer to this trajectory as the MFR scenario. We also delay the NP scenario from 2035 to 2050 to represent a slower emission reduction pathway (referred to as the NPDelayed scenario). As a reference, a close to constant emission scenario (except a slight increase of emissions to $1960 \mathrm{Mg} \mathrm{yr}^{-1}$ in 2035) is considered following the Current Policy (CP) scenario of Pacyna et al. ${ }^{8}$. This assumes that the increase in emission activity is balanced by the decrease of emission factors due to continuous emission control ${ }^{8}$.

Future MeHg exposure. We use environmental $\mathrm{Hg}$ levels to scale the food $\mathrm{Hg}$ concentrations consumed by the general population in the future under various emission change scenarios. The $\mathrm{MeHg}$ concentrations in freshwater water fish are influenced by those in their prey and ultimately by river/lake water $\mathrm{MeHg}$ levels, which are not explicitly simulated by our integrated model. Instead, we use the atmospheric deposition as a proxy as it is the major source of $\mathrm{Hg}$ in surface waters ${ }^{27}$. The rice $\mathrm{MeHg}$ concentrations are scaled by soil $\mathrm{Hg}$ concentrations due to the strong correlation between them ${ }^{28}$. We use the planktonic $\mathrm{MeHg}$ concentrations as a proxy for seafood because the uptake from seawater by plankton represents the largest concentration increase for $\mathrm{MeHg}$ biomagnification in marine food webs ${ }^{29}$.

We find that atmospheric $\mathrm{Hg}$ deposition and marine planktonic $\mathrm{MeHg}$ are highly sensitive to future $\mathrm{Hg}$ emissions (Fig. 3). The atmosphere, ocean, and their exchange are simulated by the GEOS-Chem and MITgcm models, both driven by the meteorological/ocean physical data from climate models. The marine plankton biomass and community structure are modeled by an ecosystem model (see "Methods" for more details and a model evaluation against observations is in Figs. S1-3). The model simulates higher deposition over source regions (e.g., East Asia, West Europe, and North America), regions covered with forests that have larger dry deposition velocity (e.g., South America), and over ocean regions with high precipitations (Fig. 3a). Higher planktonic $\mathrm{MeHg}$ concentrations are modeled over productive regions (e.g., high-latitudes and the eastern tropical oceans) (Fig. 3c). The model projects that the MFR and NP-Delayed scenarios reduce the atmospheric deposition in 2050 by $48 \%$ and $28 \%$, respectively, compared to the CP scenario. Overall, the decrease of $\mathrm{Hg}$ deposition is smaller than that of anthropogenic emissions ( $85 \%$ and $48 \%$, respectively, Fig. 2) because primary emissions only account for $20-30 \%$ of total atmospheric $\mathrm{Hg}$ emissions ${ }^{10}$. Similarly, the $\mathrm{A} 1 \mathrm{~B}$ and the A2 scenarios project an increase of primary atmospheric emissions by $150 \%$ and $99 \%$, respectively, which only translate to an increase of deposition by $87 \%$ and $59 \%$, respectively. The percentage change of planktonic $\mathrm{MeHg}$ concentrations is similar to atmospheric deposition, since inorganic $\mathrm{Hg}$, which is the substrate of $\mathrm{MeHg}$ in the seawater, is mainly from atmospheric deposition $^{30}$. The percentage changes for different regions are predicted to be fairly uniform. Contrasting to atmospheric deposition, the changes in soil $\mathrm{Hg}$ concentrations are much smaller, ranging from $-3 \%$ to $4 \%$ for different scenarios in 2050 . This is because of the large mass and long lifetime of $\mathrm{Hg}$ in this reservoir ${ }^{31,32}$

Health effects. The CP scenario projects a flat trend for the global total IQ decrease until 2050 (an increase from 11.1 to $11.6 \times 10^{6}$ pts during 2010-2050) (Fig. 4a), reflecting similar trends in both total MeHg exposure (Fig. 3) and new birth number (World Population Prospects: https://population.un.org). We find the changes in future primary anthropogenic emissions are substantially dampened for their health effects. The total IQ decrease in 2050 predicted by the MFR and NP-Delayed scenarios are $24 \%$ and $15 \%$ lower than that of the $\mathrm{CP}$ scenario, respectively, even though the anthropogenic emissions have been projected to decrease by $85 \%$ and $48 \%$, respectively. The A1B and A2 scenarios predict a $51 \%$ and $34 \%$ increase in the IQ effect, respectively, whereas the changes in primary emissions are $150 \%$ and $99 \%$, respectively.

The global population is projected to increase by $~ 40 \%$ to 9.7 billion in 2050 (World Population Prospects), which translates to the projected FHA deaths associated with $\mathrm{MeHg}$ exposure by $43 \%$ to 40,000 per year for the CP scenario. This results in a cumulative death of 1.6 million during 2010-2050. The increase in total population also cancels the decreasing trend in per-capita exposure of the MFR and NP-Delayed scenarios. The projected trajectory for the deaths of these two scenarios is quite flat, with a cumulative death of 1.4 and 1.5 million, respectively (Fig. 4b). In contrast, the projected deaths for A1B and A2 scenarios are 120\% and $94 \%$ higher than the level in 2010 , amounting to a cumulative death of 2.0 and 1.9 million, respectively.

The economic valuation of these two health endpoints relies on the projection of the global economy. We adopt the middle-ofthe-road pathway projected by the Shared Socioeconomic Pathways (SSP2) in the $21^{\text {st }}$ century (https://tntcat.iiasa.ac.at/SspDb). Due to the increase in per-capita GDP, the total economic loss of the CP scenario is projected to increase by a factor of 2.3 , and the loss for the strictest emission reduction scenario, MFR, also increases by a factor of 1.4 (Fig. 4c). The cumulative economic loss for the CP scenario is $\$ 19$ trillion (2020 USD, discounted to 2050 at a rate of $3 \%$ ). The projected health benefits of the MFR and NP-Delayed scenarios compared to the CP scenario are \$2.4 trillion and $\$ 1.5$ trillion, respectively. On the other hand, the A1B and A2 scenarios will result in an additional loss of $\$ 4.9$ trillion and $\$ 3.3$ trillion, respectively. The two health endpoints contribute roughly equally to the total loss; however, the contribution from the VSL of FHA becomes more dominant $(60 \%)$ in 2050 due to a faster increase in total population than new birth. 


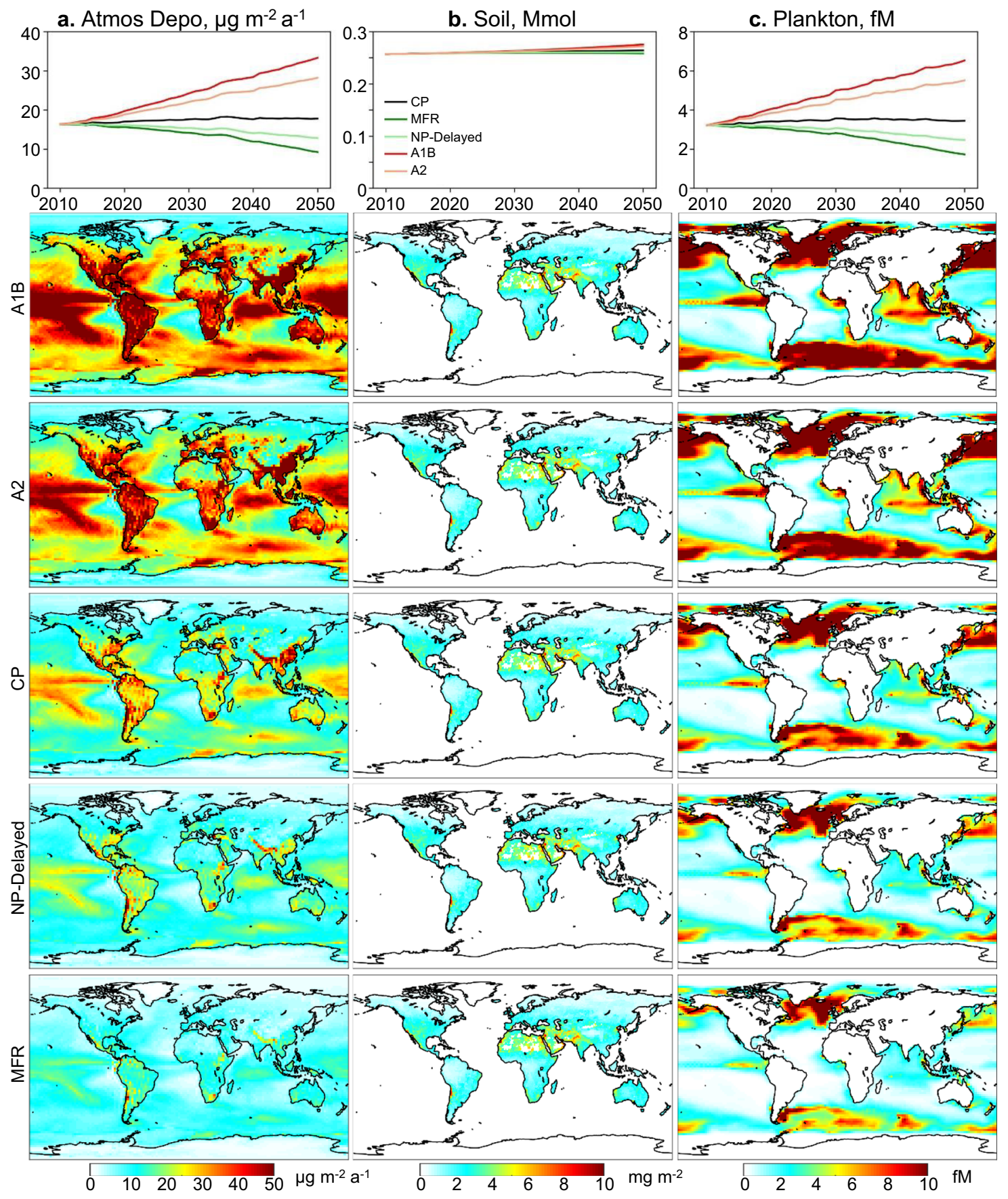

Fig. 3 Projected mercury levels in the environment in 2050. The column (a), (b), and (c) is for atmospheric deposition, soil, and marine plankton, respectively. For each column, the top panel shows the trend of global mean values, while the lower panels are the spatial distribution for the five scenarios (with emission from highest to lowest): A1B (business as usual), A2 (divided world scenario), CP (current policy), NP-Delayed (new policy delayed), and MFR (maximum feasible reduction).

Uncertainty. We assess the uncertainty and variability of the health effects projected by our integrated model by identifying key driving factors, including food consumption data, food $\mathrm{MeHg}$ concentrations, dose-response parameters linking $\mathrm{MeHg}$ exposure and health effects, and economic valuation (Fig. 5). We rely on the database of the United Nations' Food and Agriculture Organization (FAO, http://www.fao.org) for food consumption. Compared with national data, the two data sources generally agree within a factor of 2 (Figure S6). This reflects both the different survey methods and variability among the population ${ }^{33,34}$. This results in a variability of cumulative economic loss for the CP scenario as $\$ 10$ to $\$ 27$ trillion (95\% confidence interval in 2020 value and realized in 2050, same thereafter). This variability also propagates to the estimated benefits (or extra costs) for other scenarios (Fig. 5). By considering the log-normal distributions of food $\mathrm{MeHg}$ data, the cumulative effects for the CP scenario would range from $\$ 12$ to $\$ 31$ trillion. This indicates that the food intake and $\mathrm{MeHg}$ data contribute roughly equally to the uncertainty of exposure calculation. We find that the dose-response functions between $\mathrm{MeHg}$ intake and health effects have the largest contribution to the uncertainty, ranging from nearly $\$ 7.8$ to $\$ 47$ trillion. This reflects 

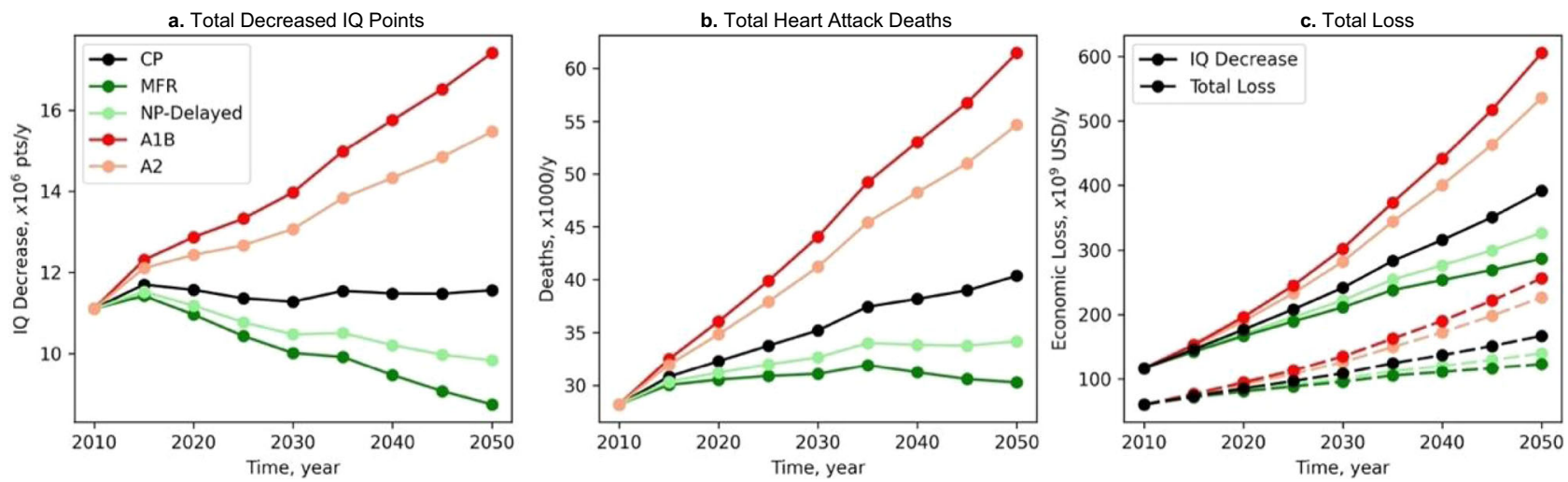

Fig. 4 Trajectories of global annual health effects associated with different future emission scenarios. (a) Total intelligence quotient (IQ) decrements of newborns; (b) Total heart attack deaths; (c) Economic valuation of health effects: total valuation (solid lines) and from IQ decrements (dashed lines). Five scenarios are included: A1B (business as usual), A2 (divided world scenario), CP (current policy), NP-Delayed (new policy delayed), and MFR (maximum feasible reduction).

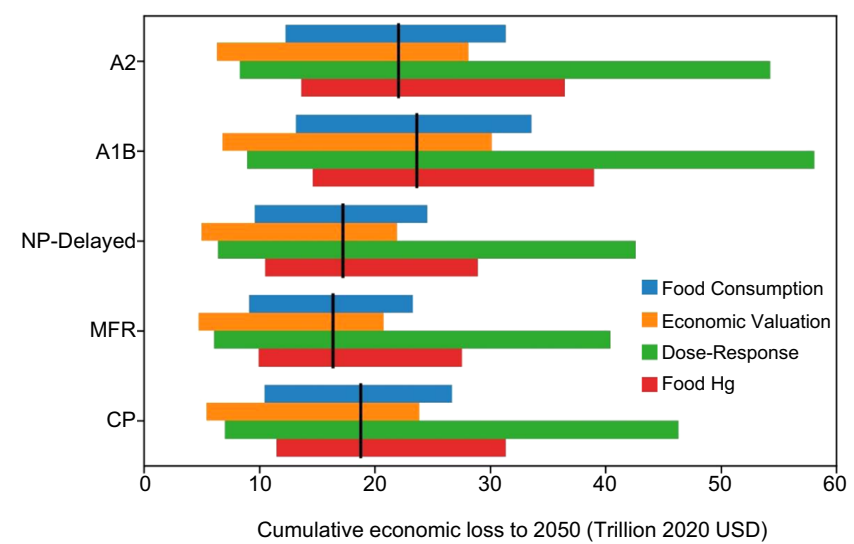

Fig. 5 Range in cumulative health impacts (unit: US dollars in 2020 value) to 2050 for the CP (current policy), MFR (maximum feasible reduction), NP-Delayed (new policy delayed), A1B (business as usual), and A2 (divided world scenario) scenarios. Bars indicate the sensitivity of cumulative health effects to high and low case assumptions for uncertain parameters (as 95\% confidence intervals): food consumption, economic valuation, dose-response parameterization, and food methylmercury concentrations. The black lines are our best estimates.

the large variability in the coefficients for IQ decrement and heart attack risk per unit hair $\mathrm{Hg}$ increase ${ }^{11,35}$, despite convincing evidence for the association between $\mathrm{MeHg}$ exposure and human health impact ${ }^{36}$. The pharmacokinetics parameters to link food exposure to blood and hair $\mathrm{Hg}$ levels play a much smaller role with a variability of $10-20 \%$. Another source of uncertainty comes from the parameters for economic valuation, especially the VSL of heart attack deaths (a factor of 10) ${ }^{11}$. Using high and low assumptions for the economic valuation leads to a range of $\$ 5.8-24$ trillion for the health effect of the CP scenario. By taking a Monte Carlo approach (see Methods), we also calculate the overall uncertainty range as $\$ 4.7-54$ trillion.

Our ability to model the $\mathrm{MeHg}$ exposure and risk is limited by existing scientific knowledge and data, such as the food web dynamics of $\mathrm{MeHg}$ in higher trophic levels and the dose-response relationships between $\mathrm{MeHg}$ exposure and its health effects (Fig. 5). The future $\mathrm{Hg}$ emissions to water and soil are subjected to change ${ }^{37}$. We only consider the general populations, but not the so called high exposure population groups ${ }^{24}$. The fishery harvest and human food consumption patterns will also change in the future ${ }^{38}$. Our results do not show strong interannual variability for environmental $\mathrm{Hg}$ levels on a global scale, but the change in dietary structure and food web dynamics in high trophic levels that are not covered in this model may amplify these variabilities, especially at regional scales ${ }^{39}$. The permafrost stores a large amount of $\mathrm{Hg}$ and may serve as a potential $\mathrm{Hg}$ source as a consequence of thawing ${ }^{31}$. There are likely other health endpoints not considered in this study due to the limited epidemiological data ${ }^{36}$. Our assessment is thus considered illustrative and not a comprehensive projection of impacts. However, much uncertainty of the model framework could be reduced using a similar methodology as science and data evolve.

Policy implications. This study develops and applies a comprehensive climate-atmosphere-land-ocean-ecosystem and exposurerisk model framework for global toxic pollution from Hg. We show that the annual global health risk associated with $\mathrm{MeHg}$ exposure at present-day is $\$ 117$ billion (2020 value), contributed by $1.2 \times 10^{7}$ points of IQ loss and 29,000 heart attack deaths per year. By 2050, the cumulative health effects are projected to be $\$ 19$ (\$10-27 as uncertainty range) trillion (discount rate of 3\% to 2050). Compared to the CP scenario, the MFR and NP-Delayed scenarios have benefits of $\$ 2.4$ and $\$ 1.5$ trillion, respectively, while the $\mathrm{A} 1 \mathrm{~B}$ and $\mathrm{A} 2$ scenarios have additional losses of $\$ 4.9$ and $\$ 3.3$ trillion, respectively.

Food intake structure is an important factor for $\mathrm{MeHg}$ exposure and risk. Globally, seafood consumption contributes $56 \%$ to the total $\mathrm{MeHg}$ exposure, with freshwater fish and rice contributing $34 \%$ and $10 \%$, respectively. Coastal and island countries with access to more seafood have the largest seafood consumption and they will have the greatest health benefits if $\mathrm{Hg}$ emissions are reduced in the future. Freshwater fish consumption is the highest in Asian countries, where fish is often raised in rice paddies $^{40}$. The rice consumption in these countries is also high. Despite the elevated $\mathrm{MeHg}$ exposure risk, the overall health effects of fish consumption may be positive if considering the intake of n-3 polyunsaturated fatty acids, vitamins, and other nutrients ${ }^{41}$. Another important influencing factor is the trophic level of fish/aquatic animals. The mean $\mathrm{Hg}$ levels vary for $\sim 10$ times between the lowest and highest trophic levels, much larger than the impact of water types and whether wild-caught or farmraised (Fig. S7). Dietary guidance on fish selection but not the total fish consumption is the rule of thumb to minimize the overall health risks, especially considering the nutrient effects of fish $^{42,43}$. For countries with the least $\mathrm{MeHg}$ exposure as found in this study, such as Ethiopia, Tajikistan, and Afghanistan, which are listed as the countries with serious levels of hunger (Global Hunger Index: https://www.globalhungerindex.org). In these 
countries, the MeHg exposure risk of fish consumption is even more outweighed by its nutrient benefits ${ }^{44}$. We suggest that the $\mathrm{Hg}$ level in rice is the most recalcitrant to emission reduction among the three major food categories, and the global contribution from rice consumption could increase to $23 \%$ in 2050 under the MFR scenario, which makes limiting rice consumption may be a more important $\mathrm{Hg}$ exposure mitigation strategy then.

This study focuses on the $\mathrm{MeHg}$ exposure of the general population. Significantly higher exposure and biomarker levels are found for populations exposed to $\mathrm{Hg}$ from point sources (e.g., ASGM workers) and populations with high seafood consumption (e.g., Arctic populations that consumes a lot of marine mammals, tropical riverine communities, and coastal and/or small-island communities ${ }^{24}$. Although we do not include these two groups due to the lack of global-scale data, to include them will supplement our estimate of $\mathrm{MeHg}$ exposure and health risk. With the future improvement of spatial resolution in exposure and risk modeling, our model could also be a useful tool to identify populations that are vulnerable to $\mathrm{Hg}$ exposure ${ }^{45}$.

We show that the cumulative health effects realized within the 2050 time horizon are not responding linearly with emission changes. The MFR scenario with a rather low emission level in $2050\left(300 \mathrm{Mg} \mathrm{yr}^{-1}\right)$ is only $13 \%$ lower than the CP scenario. This is associated with the relatively small change in emissions between the two scenarios in the early years (e.g., during 2010-2025), which contributes a large portion to the cumulative health effect realized in 2050 due to its compound interest. Delaying the MFR scenario (i.e., the NP-Delayed scenario) would further reduce the benefit by $38 \%$, not to mention the substantially increased health effects projected for the A1B and A2 scenarios. Even though these estimates are very sensitive to choices of the temporal scope of analysis and evaluation parameters (e.g., VSL, discounting rate) ${ }^{11}$, our results demonstrate the necessity of emission reduction sooner.

The inclusion of land and ocean in our model enables us to directly model the contribution of legacy sources (re-emissions from soil and ocean) without using a scale function ${ }^{46}$ or box models ${ }^{19}$. The inclusion of the ocean model coupled with the plankton ecosystem in our integrated model is of great interest because seafood consumption is the major exposure pathway in most countries (Fig. S5). The marine plankton and soil $\mathrm{Hg}$ concentrations are better proxy data to scale the future change of seafood and rice $\mathrm{Hg}$ levels, respectively, than atmospheric deposition that is often employed in previous studies ${ }^{5,11}$.

Our model framework provides a much-needed tool for parties to evaluate the effectiveness of the implementation of the Minamata Convention, especially to assess the response of environmental $\mathrm{Hg}$ levels to emission reduction and its implications to human exposure and health risk. Detailed scenario studies using our model framework could be conducted to evaluate and prioritize the health benefits of individual policy measures. For example, as the largest emission source, the control of ASGM is left decided for individual parties and the future emissions have large uncertainty. Our model framework would assist related countries to make their national action plans.

\section{Methods}

Mercury transport model. We develop a model framework to simulate the fate and transport of $\mathrm{Hg}$ in the Earth system that includes climate, atmosphere, land, ocean, and marine ecosystem (Fig. 6). Three-dimensional atmospheric (GEOS-Chem) and oceanic $(\mathrm{MITg} \mathrm{cm})$ transport models for $\mathrm{Hg}$ are coupled online with a twodimensional terrestrial mercury model (GTMM). These models are driven by predicted meteorological and ocean circulation data from climate models (GISS GCM ModelE2 and IGSM, respectively). Biogeochemical parameters important for $\mathrm{Hg}$ transformation are taken from a marine plankton ecosystem model (Darwin), which is also driven by the IGSM model. The details of these models are elaborated below.

We use the output of the Integrated Global System Modeling (IGSM) framework for the future climate simulated by Sokolov et al. ${ }^{47}$ and Dutkiewicz et al. ${ }^{48}$. Briefly, the model framework includes a three-dimensional ocean model that has a horizontal resolution of $2^{\circ} \times 2.5^{\circ}$ and 22 vertical levels from $10 \mathrm{~m}$ in the surface to $500 \mathrm{~m}$ at depth, and a two-dimensional (latitude and height) atmosphere physical and chemical model. The framework has a terrestrial component with hydrology, vegetation, and natural emissions. The model is run with a preindustrial level of greenhouse gas concentration for 2000 years as spin up and then for 1860-2000 with observed GHG levels. For the 21st century, a business as usual scenario (close to IPCC AR5 RCP8.5 scenario) is assumed for anthropogenic emissions. We use the IGSM archived monthly mean ocean physics data such as seawater temperature, ocean current velocities, and mixing conditions to drive the MITgcm model ${ }^{48}$.

As the IGSM only contains a two-dimensional atmosphere module, we use the archived future climate data simulated by the NASA Goddard Institute for Space Studies (GISS) general circulation model (GCM) (ModelE2) to drive the GEOSChem model ${ }^{49}$. The model has a horizontal resolution of $2^{\circ} \times 2.5^{\circ}$ for the atmosphere, land surface, ocean, and sea ice models. The three-dimensional atmosphere model has 40 vertical levels from the surface to $0.002 \mathrm{hPa}(\sim 85 \mathrm{~km}$ altitude). The greenhouse gas concentrations are specified following the IPCC AR5 RCP8.5 scenario. The meteorology fields such as temperature and precipitation are archived with a frequency of 3-6 h. The discrepancies between these two climate models are minimal due to the similar pathways of greenhouse gas concentrations in the 21 st century.

The ocean biogeochemistry and ecosystem data are from the Darwin model within the MITgcm framework simulated by Dutkiewicz et al. ${ }^{48}$ during the 21 st century. This model is driven by the archived ocean physics fields from the IGSM. The transport of inorganic and organic forms of carbon, nitrogen, phosphorus, iron, and silica are included. The model includes six phytoplankton functional groups and two zooplankton grazers (namely diatoms, other large phytoplankton, diazotroph, coccolithophore, Prochlorococcus, Synechococcus, and small and large herbivorous plankton). The model simulates biogeochemical processes including phytoplankton growth, zooplankton grazing, zooplankton mortality, and the formation and transformation of particulate and dissolved organic matters. The monthly mean concentrations of organic carbon and plankton biomass, and the rates of plankton growth, grazing, and mortality are archived to drive the $\mathrm{Hg}$ component of the model.

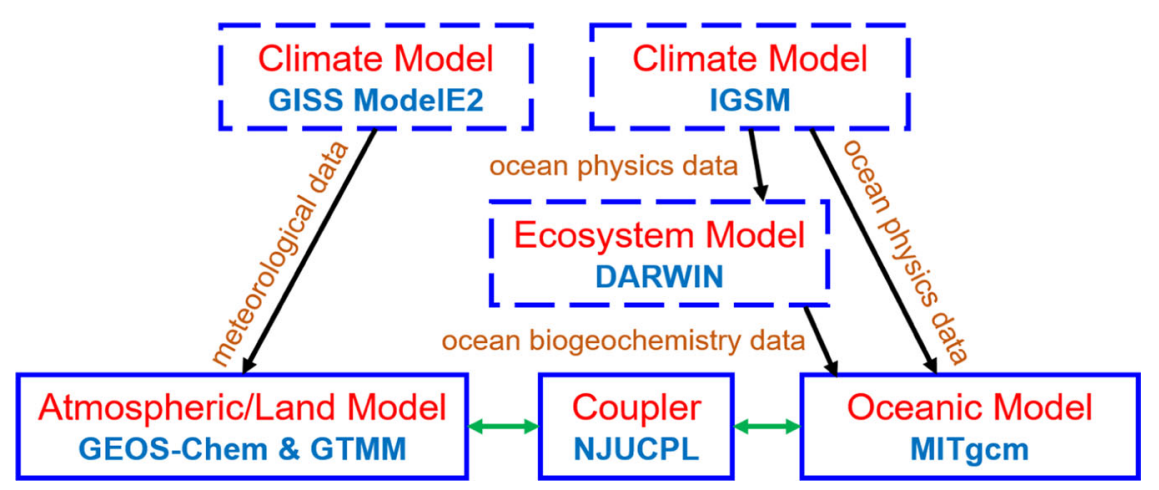

Fig. 6 The model framework used in this study. Blue boxes represent models while arrows indicate data flows. Models with dashed boxes are run by previous studies and we directly use their archived output, while those with solid lines are run in this study. Black arrows mean feeding of archived data from one model to another (i.e., models are run separately), while green arrows mean running two models simultaneously with online data exchange. 
We simulate the chemistry, transport, and trophic transfer of $\mathrm{Hg}$ in the ocean using the MITgcm following Zhang et al. ${ }^{30}$. The model is driven by ocean physics data from the IGSM and biogeochemical parameters from the Darwin model. The model has the same grid as the ocean component of the IGSM. The model simulates 14 tracers that include elemental $\mathrm{Hg}$, oxidized $\mathrm{Hg}$, monomethylmercury $(\mathrm{MMHg})$, dimethylmercury $(\mathrm{DMHg})$, particulate-bound inorganic $\mathrm{Hg}$, and particulate-bound MMHg, and MMHg in plankton (six phytoplankton groups and two zooplankton types). The model includes a detailed photo- and biological mediated redox chemistry of inorganic $\mathrm{Hg}$, and the transformation with methylated $\mathrm{Hg}$ species. The bioaccumulation and biomagnification of $\mathrm{MMHg}$ in the marine plankton food web is simulated following Zhang et al. ${ }^{30}$.

The atmospheric chemistry and transport of $\mathrm{Hg}$ are simulated by the GEOSChem model following Horowitz et al. ${ }^{10}$. The model is based on version v9-02 (www.geos-chem.org). The model has the same resolution as the GISS GCM ModelE2 model and is driven by its archived meteorology fields. The simulated chemistry includes three forms of $\mathrm{Hg}$ in the atmosphere: gaseous elemental, gaseous oxidized, and particle-bound $\mathrm{Hg}$. The redox chemistry of $\mathrm{Hg}$ is modeled following Horowitz et al. ${ }^{10}$. The chemistry includes two-stage oxidation of elemental $\mathrm{Hg}$ by bromine atoms and photoreduction of oxidized $\mathrm{Hg}$ in cloud droplets. Concentrations of related chemical species are taken from GEOS-Chem simulation of tropospheric oxidant-aerosol chemistry ${ }^{50}$. The model also includes geogenic and biomass burning sources, as well as reemissions from snow reservoirs ${ }^{10}$.

The soil pool and land-atmosphere exchange of $\mathrm{Hg}$ are simulated using the GTMM model ${ }^{32}$. The model has a horizontal resolution of $1^{\circ} \times 1^{\circ}$ and covers the top $30 \mathrm{~cm}$ of soils. The model takes the atmospheric deposition of both elemental and oxidized $\mathrm{Hg}$ from GEOS-Chem as input. This part of $\mathrm{Hg}$ is assumed to be loosely adsorbed to soil and leaf surfaces and undergoes photoreduction and revolatilization. Part of the $\mathrm{Hg}$ can reach to soil pool through litterfall. The model considers four soil $\mathrm{Hg}$ pools that are tied to carbon pools with characteristic turnover time ranged from $10^{0}$ to $10^{4}$ years. Hg bound to different soil carbon pools can be transformed between each other, and $\mathrm{Hg}$ is released to the atmosphere when the soil carbon is respired by microbial activities. The model is run for 30,000 years with atmospheric deposition at pre-industrial levels before ramped up with monthly deposition from 1840 to $2000^{32}$.

The GEOS-Chem, GTMM, and MITgcm Hg models are online two-way coupled using a coupler (NJUCPL) following Zhang et al. ${ }^{51}$. With a frequency of $60 \mathrm{~min}$, atmospheric $\mathrm{Hg}$ concentration and deposition data are passed from GEOSChem to GTMM and MITgcm, and soil re-emission and ocean evasion fluxes are passed from GTMM and MITgcm to GEOS-Chem, respectively. The initial conditions of these models are taken from previous simulations for the presentday $10,30,32$

The total anthropogenic $\mathrm{Hg}$ emissions for the future are taken from Streets et al. ${ }^{7}$ and Pacyna et al. ${ }^{8}$. Five policy scenarios are developed for the emissions during 2010-2050 (Fig. 2). These global total emissions are spatially distributed to each model grid based on the WHET emission inventory for $2010^{52}$. The spatial distribution and speciation of $\mathrm{Hg}$ emissions are assumed to keep constant during the model period. The model is run from 2010 to 2050 for each emission scenario.

Mercury exposure modeling. Figure 7 summarizes the approach we use to estimate $\mathrm{MeHg}$ exposure and risk. The $\mathrm{MeHg}$ exposure via three food categories is considered in this study: seafood, freshwater fish (including aquatic animals), and rice. Other types of food are ignored because of less data and much lower $\mathrm{MeHg}$ concentrations. The per-capita consumption of different food categories (including rice, total fish and aquatic animals) for each country is taken from the database of the Food and Agriculture Organization of the United Nations (UN FAO, http:// www.fao.org).
A database for the average $\mathrm{MeHg}$ concentrations of these food categories is developed by collecting available data from the literature (a full list of literature is provided in the Supporting Information). There is a total of 210,000 data points (208,000 for fish/aquatic animals and 6,400 for rice) collected from 395 publications (data handled by Microsoft Excel 2019). We exclude the data points near point sources or contaminated sites. The fish/aquatic animals are further divided into two categories: farm-raised and wild-caught with fractions from the UN FAO database. Due to the large concentration variability and the lack of fish/ aquatic animals consumption data for individual species, we group the fish/aquatic animals into four tropic level bins: $2-2.5,2.5-3.5,3.5-4.5$, and $4.5-5$, and the geometric mean of $\mathrm{MeHg}$ concentrations for each trophic level bin is calculated. The trophic level of each fish with reported $\mathrm{MeHg}$ concentration and consumption data is from the Fishbase Database (https://www.fishbase.org). The fraction of fish consumption for each trophic level bin is estimated based on the marine trophic index if detailed consumption inventory is missing (http://www.seaaroundus.org/ mti-fib-rmti/). We use the global geometric mean concentrations for countries without data. The total $\mathrm{MeHg}$ exposure $(E)$ for the general population from each country is calculated as:

$$
E=\sum_{i=1}^{4} I_{i, j}^{\mathrm{FW} \text { fish }} C_{i, j}^{\mathrm{FW} \text { fish }}+\sum_{i=1}^{4} I_{i, j}^{\text {seafood }} C_{i, j}^{\text {seafood }}+I^{\text {rice }} C^{\text {rice }}
$$

where $I$ and $C$ are for food intake and $\mathrm{MeHg}$ concentrations, respectively, for each category [freshwater (FW) fish, seafood, and rice] and trophic level bin $i(2-2.5$, 2.5-3.5, 3.5-4.5, and 4.5-5) (Fig. 7). The agreement with human biomarker data suggests that our simplified exposure model works reasonably well.

Future mercury exposure. We scale the future population exposure of $\mathrm{MeHg}$ based on the exposure level at present-day and the model-projected environmental $\mathrm{Hg}$ levels (Fig. 7). Due to the lack of data, the food consumption pattern is held constant during 2010-2050. The freshwater fish and rice $\mathrm{MeHg}$ concentrations for individual countries in a given year are assumed to be proportional to the average total $\mathrm{Hg}$ atmospheric deposition $(D)^{5,11}$ and total soil $\mathrm{Hg}$ concentration $(S)^{28}$ in the corresponding country, respectively. For the seafood, we assume the $\mathrm{MeHg}$ exposure of each country for a given year is proportional to the global average plankton $\mathrm{MeHg}$ concentrations weighted by the spatial distribution of fish harvest $(P)^{53}$ :

$$
\begin{aligned}
C_{\text {year }}^{\mathrm{FW} \text { fish }} & =C_{2010}^{\mathrm{FW} \text { fish }} \frac{D_{\text {year }}}{D_{2010}} \\
C_{\text {year }}^{\text {rice }} & =C_{2010}^{\text {rice }} \frac{S_{\text {year }}}{S_{2010}} \\
C_{\text {year }}^{\text {seafod }} & =C_{2010}^{\text {seafood }} \frac{P_{\text {year }}}{P_{2010}}
\end{aligned}
$$

Human health impact. We include two health endpoints in benefit estimates: decrement in IQ of newborns and fatal heart attack (FHA) ${ }^{5,11,16}$. A linear doseresponse relationship without thresholds is recommended by the National Research Council (NRC) between MeHg intake and fetal IQ decrements':

$$
\Delta \mathrm{IQ}=\gamma \lambda \beta \times \Delta \mathrm{EDI} \times \mathrm{BW}
$$

where $\Delta \mathrm{IQ}$ is the changes in IQ (points), $\Delta \mathrm{EDI}$ is the changes in estimated daily intake (EDI) of MeHg, and BW is the average body weight for female adults. The coefficients $\beta\left(0.6 \mu \mathrm{g} \mathrm{L}^{-1}\right.$ per $\left.\mu \mathrm{g} \mathrm{day}^{-1}\right), \lambda\left(0.2 \mu \mathrm{g} \mathrm{g}^{-1}\right.$ per $\left.\mu \mathrm{g} \mathrm{L}^{-1}\right)$, and $\gamma(0.3 \mathrm{IQ}$ points per $\mu \mathrm{g} \mathrm{g}^{-1}$ ) convert from MeHg intake to blood concentration, blood concentrations to hair concentrations, and hair concentrations to IQ decrements,

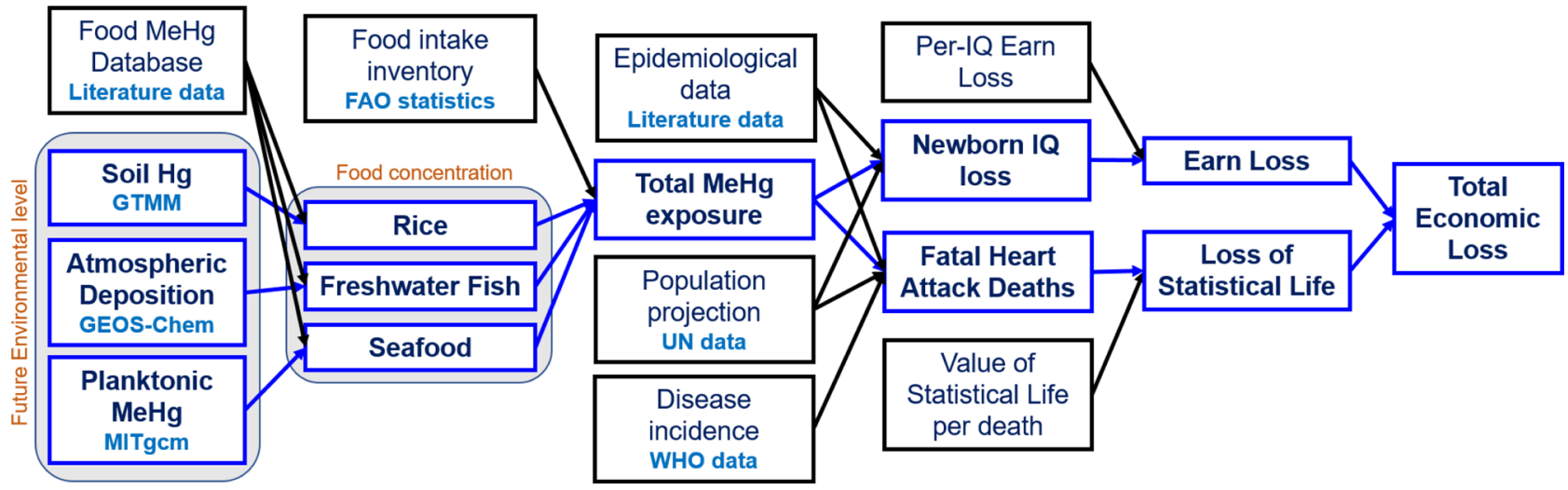

Fig. 7 Diagram for the approach and data sources for methylmercury exposure and risk calculation in this study. Blue frames represent model calculated variables, while black ones are for literature data. 
respectively. The total IQ decrements are calculated by multiplying per-fetus IQ decrements and the number of newborns, which are taken from the World Population Prospects by the UN database (https://population.un.org). This database includes projections of the total population of both sexes and newborns for each country to 2100

A log-linear dose-response relationship between $\mathrm{MeHg}$ intake and Hg-related fatal heart attacks is used in this study ${ }^{5}$ :

$$
\Delta \mathrm{CF}=\sum_{g} \mathrm{POP}_{g} \times \mathrm{Cf}_{g} \times \omega \times\left(1-\mathrm{e}^{-\varphi \lambda \beta \times \Delta \mathrm{EDI} \times \mathrm{BW}}\right)
$$

where $\triangle \mathrm{CF}$ is the changes in the deaths from fatal heart attacks associated with $\mathrm{MeHg}$ exposure, $\mathrm{POP}_{\mathrm{g}}$ is the population of gender $g$ (male and female) from World Population Prospects, and $\mathrm{Cf}_{\mathrm{g}}$ is the age-adjusted incidence of FHA of gender $g$ from Global Health Estimates by World Health Organization (http://www.who.int/ healthinfo/global_burden_disease). The coefficient $\varphi\left(0.066\right.$ per $\left.\mu \mathrm{g} \mathrm{g}^{-1}\right)$ converts hair $\mathrm{MeHg}$ concentrations to fatal heart attack risks. The subjective coefficient $\omega$ (0.33) represents the probability of the causality of the associations, reflecting the substantial uncertainties due to limited epidemiological studies.

For model evaluation, we also calculated the averaged $\mathrm{Hg}$ concentrations in the blood $\left(C^{\text {blood }}\right)$ and the hair $\left(C^{\text {hair }}\right)$ :

$$
\begin{gathered}
C^{\text {blood }}=\beta \times \mathrm{EDI} \times \mathrm{BW} \\
C^{\text {hair }}=\lambda \times C^{\text {blood }}
\end{gathered}
$$

The modeled $\mathrm{Hg}$ biomarker concentrations for individual countries are compared with the geometric mean of measured data (961,000 data points) from 245 publications for 83 countries and regions (a full list of literature is provided in the Supporting Information). The blood and hair $\mathrm{Hg}$ concentrations for general population are used by excluding high exposure group data (high fish consumption population or population exposed to point $\mathrm{Hg}$ sources such as ASGM and $\mathrm{Hg}$ mines).

Economic valuation. The IQ decrements are converted to monetary values using $\$ 18,832$ (2008 value) per IQ point normalized by the ratio between the PPPadjusted GDP per capita in each country and the US ${ }^{3}$. The economic loss from FHA deaths associated with $\mathrm{MeHg}$ exposure is calculated by a value of statistical life (VSL) approach. We adopt a VSL per death of $\$ 6.3$ million (2005 value) following Giang and Selin ${ }^{11}$. This value is also normalized by the PPP-adjusted GDP per capita in each country. The sum of these two endpoints is calculated as the total economic loss. The economic data is taken from the shared socioeconomic pathways database that projects the GDP growth for each country in the 21st century (https://tntcat.iiasa.ac.at/SspDb). We use the SSP2 scenario that assumes a median level of GDP growth rate. A discount rate of 3\% is used to realize the economic loss from 2010-2050 to $2050^{11}$.

Uncertainty analysis. We consider the contribution of the data and parameters for food consumption, food $\mathrm{MeHg}$ concentrations, dose-effect relationship, and economic valuation to the total uncertainty. We compare the food consumption data from UN FAO with national datasets (details available in the Supporting Information). The difference between them is used to represent the uncertainty range of the FAO datasets. For food $\mathrm{MeHg}$ concentration, we use the variability of the logtransformed concentrations in each food category to represent its uncertainty. We use the ranges (or standard deviations) of the dose-effect relationship between $\mathrm{MeHg}$ exposure and its health effect summarized by Chen et al. ${ }^{5}$ and Giang and Selin ${ }^{11}$. For per-IQ earn loss, we use a high- and low-end value of $\$ 18,832$ and $\$ 8013$, respectively ${ }^{11}$. The VSL per death ranges from $\$ 1$ to $\$ 10$ million following Giang \& Selin ${ }^{11}$. The overall uncertainty is estimated by a Monte Carlo approach. The health risk calculation is repeated for 1000 times with randomly sampled parameters for these four factors following Chen et al. ${ }^{5}$. The $2.5 \%$ and $97.5 \%$ percentiles of the calculated risk are taken as the overall uncertainty range (i.e., 95\% confidence interval). The exposure and risk calculation and the associated uncertainty analysis are conducted using Python 3.8.

Reporting summary. Further information on research design is available in the Nature Research Reporting Summary linked to this article.

\section{Data availability}

All data generated or analyzed during this study are available in the Supplementary Information and the research group website: https://www.ebmg.online/mercury. FAO/ WHO global individual food consumption database: http://www.fao.org/nutrition/ assessment/food-consumption-database/en/. World population prospects: https:// population.un.org. Shared socioeconomic pathways database: https://tntcat.iiasa.ac.at/ SspDb. Global hunger index: https://www.globalhungerindex.org. Fishbase database: https://www.fishbase.org. Marine trophic index: http://www.seaaroundus.org/mti-fibrmti/. Global health estimates: http://www.who.int/healthinfo/global_burden_disease.

\section{Code availability}

All model code is available at the research group website: https://www.ebmg.online/ mercury.
Received: 25 December 2020; Accepted: 27 April 2021;

Published online: 24 May 2021

\section{References}

1. Axelrad, D. A., Bellinger, D. C., Ryan, L. M. \& Woodruff, T. J. Doseresponse relationship of prenatal mercury exposure and IQ: An integrative analysis of epidemiologic data. Environ. Health Perspect. 115, 609-615 (2007).

2. Roman, H. A. et al. Evaluation of the cardiovascular effects of methylmercury exposures: Current evidence supports development of a dose-response function for regulatory benefits analysis. Environ. Health Perspect. 119, 607-614 (2011)

3. Bellanger, M. et al. Economic benefits of methylmercury exposure control in Europe: monetary value of neurotoxicity prevention. Environ. Heal. 12, (2013).

4. Zhang, H., Feng, X., Larssen, T., Qiu, G. \& Vogt, R. D. In inland China, rice, rather than fish, is the major pathway for methylmercury exposure. Environ. Health Perspect. 118, 1183-1188 (2010).

5. Chen, L. et al. Trans-provincial health impacts of atmospheric mercury emissions in China. Nat. Commun. 10, 1484 (2019).

6. Grandjean, P., Pichery, C., Bellanger, M. \& Budtz-Jorgensen, E. Calculation of mercury's effects on neurodevelopment. Environ. Health Perspect. 120, A452 (2012).

7. Streets, D. G., Zhang, Q. \& Wu, Y. Projections of global mercury emissions in 2050. Environ. Sci. Technol. 43, 2983-2988 (2009).

8. Pacyna, J. M. et al. Current and future levels of mercury atmospheric pollution on a global scale. Atmos. Chem. Phys. 16, 12495-12511 (2016).

9. Selin, N. E. et al. Global 3-D land-ocean-atmosphere model for mercury: present-day versus preindustrial cycles and anthropogenic enrichment factors for deposition. Glob. Biogeochem. Cycles 22, GB2011 (2008).

10. Horowitz, H. M. et al. A new mechanism for atmospheric mercury redox chemistry: Implications for the global mercury budget. Atmos. Chem. Phys. 17, 6353-6371 (2017).

11. Giang, A. \& Selin, N. E. Benefits of mercury controls for the United States. Proc. Natl Acad. Sci. USA. 113, 286-291 (2016).

12. Schartup, A. T. et al. Climate change and overfishing increase neurotoxicant in marine predators. Nature 572, 648-650 (2019).

13. Zhang, H., Holmes, C. D. \& Wu, S. Impacts of changes in climate, land use and land cover on atmospheric mercury. Atmos. Environ. 141, 230-244 (2016).

14. Trasande, L., Landrigan, P. J. \& Schechter, C. Public health and economic consequences of methyl mercury toxicity to the developing brain. Environ. Health Perspect. 113, 590-596 (2005).

15. Spadaro, J. V. \& Rabl, A. Global health impacts and costs due to mercury emissions. Risk Anal. 28, 603-613 (2008).

16. Rice, G. E., Hammitt, J. K. \& Evans, J. S. A probabilistic characterization of the health benefits of reducing methyl mercury intake in the United States. Environ. Sci. Technol. 44, 5216-5224 (2010).

17. Griffiths, C., McGartland, A. \& Miller, M. A comparison of the monetized impact of IQ decrements from mercury emissions. Environ. Health Perspect. 115, 841-847 (2007).

18. Amos, H. M., Jacob, D. J., Streets, D. G. \& Sunderland, E. M. Legacy impacts of all-time anthropogenic emissions on the global mercury cycle. Global Biogeochem. Cycles 27, 410-421 (2013).

19. Angot, H. et al. Global and local impacts of delayed mercury mitigation efforts. Environ. Sci. Technol. 52, 12968-12977 (2018).

20. Rice, G. E. \& Hammitt, J. K. Economic valuation of human health benefits of controlling mercury emissions from U. S. coal-fired power plants. (2005). Available at: https://www.nescaum.org/documents/rpt050315mercuryhealth. pdf. (Accessed: 22nd April 2021)

21. Rothenberg, S. E., Windham-myers, L. \& Creswell, J. E. Rice methylmercury exposure and mitigation: a comprehensive review. Environ. Res. 133, 407-423 (2014).

22. Evers, D. C. et al. Common loon eggs as indicators of methylmercury availability in North America. Ecotoxicology 12, 69-81 (2003).

23. Bellinger, D. C. A strategy for comparing the contributions of environmental chemicals and other risk factors to neurodevelopment of children. Environ. Health Perspect. 120, 501-507 (2012).

24. Basu, N. et al. A state-of-the-science review of mercury biomarkers in human populations worldwide between 2000 and 2018. Environ. Health Perspect. 126, 106001 (2018).

25. Eagles-smith, C. A. et al. Modulators of mercury risk to wildlife and humans in the context of rapid global change. Ambio 47, 170-197 (2018).

26. AMAP/UNEP. Technical Background Report for the Global Mercury Assessment. Arctic Monitoring and Assessment Programme (2013). 
27. Rothenberg, S. E. \& Feng, X. Mercury cycling in a flooded rice paddy. J. Geophys. Res. Biogeosciences 117, G03003 (2012).

28. Kwon, S. Y., Selin, N. E., Giang, A., Karplus, V. J. \& Zhang, D. Present and future mercury concentrations in Chinese rice: insights from modeling. Glob. Biogeochem. Cycles 32, 437-462 (2018).

29. Schartup, A. T. et al. A model for methylmercury uptake and trophic transfer by marine plankton. Environ. Sci. Technol. 52, 654-662 (2018).

30. Zhang, Y., Soerensen, A. L., Schartup, A. T. \& Sunderland, E. M. A global model for methylmercury formation and uptake at the base of marine food webs. Glob. Biogeochem. Cycles 34, e2019GB006348 (2020).

31. Schuster, P. F. et al. Permafrost stores a globally significant amount of mercury. Geophys. Res. Lett. 45, 1463-1471 (2018).

32. Smith-Downey, N. V., Sunderland, E. M. \& Jacob, D. J. Anthropogenic impacts on global storage and emissions of mercury from terrestrial soils Insights from a new global model. J. Geophys. Res. 115, G03008 (2010).

33. Cook, A., Pryer, J. \& Shetty, P. The problem of accuracy in dietary surveys. Analysis of the over 65 UK National Diet and Nutrition Survey. J. Epidemiol. Community Health 54, 611-616 (2000).

34. Grandjean, A. C. Dietary intake data collection: challenges and limitations. Nutr. Rev. 70, S101-S104 (2012).

35. Virtanen, J. K., Rissanen, T. H., Voutilainen, S. \& Tuomainen, T. P. Mercury as a risk factor for cardiovascular diseases. J. Nutr. Biochem. 18, 75-85 (2007).

36. Karagas, M. R. et al. Evidence on the human health effects of low-level methylmercury exposure. Environ. Health Perspect. 120, 799-806 (2012).

37. Kocman, D. et al. Toward an assessment of the global inventory of presentday mercury releases to freshwater environments. Int. J. Environ. Res. Public Health 14, 138 (2017).

38. Cheung, W. W. L. The future of fishes and fisheries in the changing oceans. J. Fish. Biol. 92, 790-803 (2018).

39. Wang, F. et al. How closely do mercury trends in fish and other aquatic wildlife track those in the atmosphere? - Implications for evaluating the effectiveness of the Minamata Convention. Sci. Total Environ. 674, 58-70 (2019).

40. Halwart, M. \& Gupta, M. V. Culture of Fish in Rice Fields. FAO and The WorldFish Center (FAO and the WorldFish Center, 2004).

41. Calder, R. S. D., Bromage, S. \& Sunderland, E. M. Risk tradeoffs associated with traditional food advisories for labrador inuit. Environ. Res. 168, 496-506 (2019).

42. Xue, J. et al. Modeling tribal exposures to methyl mercury from fish consumption. Sci. Total Environ. 533, 102-109 (2015).

43. Ginsberg, G. L. \& Toal, B. F. Quantitative approach for incorporating methylmercury risks and omega-3 fatty acid benefits in developing speciesspecific fish consumption advice. Environ. Health Perspect. 117, 267-275 (2009).

44. Mozaffarian, D. \& Rimm, E. B. Fish intake, contaminants, and human health. JAMA 296, 1885-1899 (2006).

45. Undeman, E., Brown, T. N., McLachlan, M. S. \& Wania, F. Who in the world is most exposed to polychlorinated biphenyls? Using models to identify highly exposed populations. Environ. Res. Lett. 13, 064036 (2018).

46. Selin, N. E. A proposed global metric to aid mercury pollution policy. Science 360, 607-609 (2018).

47. Sokolov, A. P. et al. Probabilistic forecast for twenty-first-century climate based on uncertainties in emissions (without policy) and climate parameters. J. Clim. 22, 5175-5204 (2009).

48. Dutkiewicz, S. et al. Impact of ocean acidification on the structure of future phytoplankton communities. Nat. Clim. Chang. 5, 1002-1006 (2015).

49. Rind, D., Lerner, J., Jonas, J. \& McLinden, C. Effects of resolution and model physics on tracer transports in the NASA Goddard Institute for Space Studies general circulation models. J. Geophys. Res. 112, D09315 (2007).

50. Schmidt, J. A. et al. Modeling the observed tropospheric $\mathrm{BrO}$ background: importance of multiphase chemistry and implications for ozone, $\mathrm{OH}$, and mercury. J. Geophys. Res. Atmos. 121, 11,819-11,835 (2016).
51. Zhang, Y. et al. A coupled global atmosphere-ocean model for air-sea exchange of mercury: insights into wet deposition and atmospheric redox chemistry. Environ. Sci. Technol. 53, 5052-5061 (2019).

52. Zhang, Y. et al. Observed decrease in atmospheric mercury explained by global decline in anthropogenic emissions. Proc. Natl Acad. Sci. USA. 113, 526-531 (2016).

53. Watson, R. A. A database of global marine commercial, small-scale, illegal and unreported fisheries catch 1950-2014. Sci. Data 4, 1-9 (2017).

\section{Acknowledgements}

We gratefully acknowledge financial support from the National Natural Science Foundation of China (NNSFC) 41875148, the Chinese Academy of Science Interdisciplinary Innovation Team (JCTD-2020-20), Jiangsu Innovative and Entrepreneurial Talents Plan, the Collaborative Innovation Center of Climate Change, Jiangsu Province. We thank Aijun Ding, Bin Wang, Guoxing Li, Qingru Wu, Lars-Eric Heimbürger, Noelle Selin, and Elsie Sunderland for helpful discussions. We are grateful to the High Performance Computing Center (HPCC) of Nanjing University for doing the numerical calculations in this paper on its blade cluster system.

\section{Author contributions}

Y.Z. designed and conducted this study. Y.Z., Z.S., S.H., P.Z., Y.P., P.W., and J.G. compiled literature data. S.D, H.Z., S.W., L.C., and P.L. provided model tools or datasets. Y.Z. led the manuscript writing with supports from S.D., H.Z., S.W., F.W., L.C., S.W., and P.L.

\section{Competing interests}

The authors declare no competing interests.

\section{Additional information}

Supplementary information The online version contains supplementary material available at https://doi.org/10.1038/s41467-021-23391-7.

Correspondence and requests for materials should be addressed to Y.Z.

Peer review information Nature Communications thanks Shaojie Song and other, anonymous, reviewers for their contributions to the peer review of this work. Peer review reports are available.

Reprints and permission information is available at http://www.nature.com/reprints

Publisher's note Springer Nature remains neutral with regard to jurisdictional claims in published maps and institutional affiliations.

\begin{abstract}
(c) (i) Open Access This article is licensed under a Creative Commons c. Attribution 4.0 International License, which permits use, sharing, adaptation, distribution and reproduction in any medium or format, as long as you give appropriate credit to the original author(s) and the source, provide a link to the Creative Commons license, and indicate if changes were made. The images or other third party material in this article are included in the article's Creative Commons license, unless indicated otherwise in a credit line to the material. If material is not included in the article's Creative Commons license and your intended use is not permitted by statutory regulation or exceeds the permitted use, you will need to obtain permission directly from the copyright holder. To view a copy of this license, visit http://creativecommons.org/ licenses/by/4.0/.
\end{abstract}

(C) The Author(s) 2021 